\title{
On the Relationship between Language Proficiency and Teaching Knowledge Acquisition of English Majors at a Normal School-Based on Three Repetitive Lessons
}

\author{
Mingmei Wang \\ Sichuan University of Arts and Science, Dazhou, China
}

\begin{abstract}
Taking three high school reading repetitive lessons of two English majors with different language proficiency as samples, this paper explores the relationship between language proficiency and teaching knowledge acquisition. Through the qualitative analysis of teaching scores, teaching plans, reflective reports, interview recordings and other data, it is found that: After three repetitions, the teaching skills of the student with high language proficiency have been significantly improved. The quality of teaching design and the effectiveness of teacher's language have made remarkable progress in the second lesson. The teaching management ability and students' learning effect have gradually improved with the increase of teaching times. The abilities of the student with low language proficiency in all aspects are gradually improved with the increase of teaching times. This study has important reference significance for pre-service foreign language teacher education.
\end{abstract}

Index Terms-English majors, language proficiency, teaching knowledge, repetitive lessons

\section{INTRODUCTION}

Teaching is an art. Successful teaching requires not only teachers' solid subject knowledge, but also their skilled subject-based teaching knowledge that can process and translate the subject knowledge into the knowledge that students can easily understand (Zou \& Chen, 2005). Subject-based teaching knowledge is the integration of subject contents and educational disciplines, which can best distinguish the differences between subject experts and teachers (Shulman, 1987). Foreign language teachers are different from other subject teachers. As far as other disciplines are concerned, teaching tools are the mother tongue which is familiar to both teachers and students. The teaching process is to give and acquire teaching contents in the mother tongue. However, in foreign language teaching, both teaching tools and teaching contents are foreign languages. Foreign language teachers' job is to help students construct a all-new language and culture system with the unfamiliar language, which sets higher requirements for foreign language teachers' language proficiency and teaching ability. But the fact is that, most foreign language teachers in China are foreign language learners. They are still in the process of language development and usually do not have the language level of the native speakers. The dynamic characteristics of interlanguage make their foreign language knowledge particularly easy to change, and this change will definitely affect the development of their foreign language teaching knowledge (Zou, 2013). English majors at the normal schools are learners of foreign language knowledge and teaching knowledge. Will the change of language knowledge affect their acquisition of teaching knowledge? This paper studies this question.

\section{LITERATURE REVIEW}

Schulman, the American educator who proposed the concept of subject-based teaching knowledge, emphasized that subject-based knowledge and subject-based teaching knowledge are the core of teachers' knowledge, and there is an important relationship between them (Shulman,1987). Grossman (1990), the successor of Schulman's pedagogical knowledge theory carefully observed and compared the classes of English teachers with different levels of subject knowledge, and found that teachers with solid subject knowledge are familiar with the vertical arrangement and horizontal connection of the subject in different grades, understand the relationship among the knowledge points presented in the textbook, so they will not only reorganize the structure of textbooks, but also take effective representations according to students' actual level and on-the-spot reaction to help students establish links between knowledge points, so that students can easily enter and master unfamiliar content with familiar content as a starting point. While teachers with poor subject knowledge can not establish the knowledge structure schema of the subject, only stick to the arrangement of the textbook. The knowledge points expressed are isolated and fragmented, which makes it difficult for students to learn. The teaching content is limited to textbooks, and usually teachers-centered method is adopted to avoid student's questions. After making a qualitative study of an experienced ESL teacher's grammar knowledge and grammar teaching knowledge, Borg(1998) found that the teacher's grammar knowledge is 
closely related to his grammar teaching behavior. Through experiments, Ball \& McDiarmid et al. (1990) have proved that a good professional foundation is a necessary condition for excellent teachers. Theses research clearly shows that teachers' subject knowledge plays a decisive role in their teaching strategies, teaching contents and teaching quality. However, the above studies mainly focus on the classroom teaching of in-service teachers, research on the learning process of pre-service teachers has not been touched.

Repetitive teaching means "teachers teach the same or similar content in the same or similar teaching environment facing different teaching objects" (Chen \& Zou, 2016, p. 65). In recent years, repetitive teaching has been regarded as an effective medium for students at the normal schools to learn teaching knowledge. The main reason is that it has the following advantages: First of all, the multiple variables involved are reduced. Only the teaching objects and teaching methods are variables. The teaching content and teaching environment are invariable factors, which reduces the interference in the process of teachers' learning and is conducive to the rapid progress of the students. Secondly, it provides students with targeted learning chances. The omissions, problems and difficulties in the previous teaching will force the students to actively seek solutions to deal with the subsequent teaching. In the virtuous cycle of constantly discovering and solving problems, normal school students get the opportunity to use theory to guide practice and practice to test ideas, thus exploring and generating their own teaching practice knowledge. Existing research has proved that repetitive teaching can promote the acquisition of teaching skills of normal school students(Chen \& Zou, 2016; Xie \& Zou, 2015). For this reason, this study takes three repetitive lessons of two English majors with different language levels as samples to explore whether language proficiency will cause some difference in the acquisition of teaching knowledge.

\section{RESEARCH METHOD}

\section{A. Participants}

The participants are two female students in the fourth grade of English teachers' major in a university: Song Wei and Zhao Min (alias). Song Wei passed TEM-4 with 85 points in grade two while Zhao Min passed TEM-4 with 62 points in grade three. This study separately defines their language proficiency as high $(\mathrm{H})$ level and low (L) level. Both of them have studied "pedagogy", "psychology" and other courses, but neither has teaching any experience. They are beginners of teaching skills. This research is designed according to the teaching practice in the first semester of the fourth grade which will be carried out in the second semester. Therefore, the two students are highly motivated and have no feelings of resistance.

\section{B. Research Design}

This study was conducted in the first grade of L Middle School, which has nine parallel classes. Class 1-6 were randomly selected as the experimental units. Song Wei gave one lesson in Class 1, 3 and 5, Zhao Min gave lessons in Class 2, 4 and 6, each of them had three chances of teaching. Before the teaching, the two students went to L Middle School to observe the English class, got familiar with the students' situation, teaching facilities and so on, and communicated with the middle school teachers to determine the teaching content and time. Then, they began to prepare lessons and make teaching plans. During the teaching, the university curriculum teachers, middle school contact teachers and the other three English teachers in the middle school attended the class. After the class, they filled in reflective reports, and the teachers and some of the subjects were interviewed and recorded.

Data collation and analysis

\section{Data Analysis}

The research data include three lesson plan designs, classroom videos, reflective reports, interview recordings. All the data were organized and analyzed according to Zou's (2013) framework of classroom teaching and learning process analysis. It has four dimensions and 18 scoring items. Among them, teaching design dimension contains 4 items, teaching management dimension contains 4 items, teachers' language dimension contains 7 items and students' learning dimension contains 3 item (see Table 1 for details). 
TABLE I.

Framework OF ClassRoom TEACHING AND LEARNING PROCESS ANALYsis

\begin{tabular}{|c|c|c|}
\hline Dimensions & Focus & Items \\
\hline \multirow{4}{*}{$\begin{array}{l}\text { Teaching } \\
\text { Design }\end{array}$} & Teaching Objectives: & Clarity of presentation of teaching objectives \\
\hline & Teaching Steps & The Logic of Teaching Steps \\
\hline & Textbook Analysis & $\begin{array}{l}\text { Utilization of the Characteristics of Teaching } \\
\text { Materials }\end{array}$ \\
\hline & Instructional Tools & Effectiveness of Instructional Tools \\
\hline \multirow[t]{4}{*}{$\begin{array}{l}\text { Teaching } \\
\text { Management }\end{array}$} & \multirow{4}{*}{$\begin{array}{l}\text { Beginning, Ending, Transition, } \\
\text { Activity Organization, } \\
\text { Use of Teaching } \\
\text { Materials and Equipment, } \\
\text { Overall Activity Coherence }\end{array}$} & $\begin{array}{l}\text { Targeted Management, } \\
\text { Multitask Management }\end{array}$ \\
\hline & & $\begin{array}{l}\text { Opportunity for Promoting Activities and } \\
\text { Fluency Degree }\end{array}$ \\
\hline & & $\begin{array}{l}\text { Degree of mobilizing students and } \\
\text { student's participation }\end{array}$ \\
\hline & & $\begin{array}{l}\text { How to deal with accidents and } \\
\text { how to use teaching equipment }\end{array}$ \\
\hline \multirow{7}{*}{$\begin{array}{l}\text { Teacher } \\
\text { Language }\end{array}$} & \multirow{7}{*}{$\begin{array}{l}\text { Instructions, Interpretation, } \\
\text { Communication, Response, } \\
\text { Demonstration, Evaluation, Volume, } \\
\text { Rhythm, Language Accuracy, } \\
\text { Confidence, Body Language, Vision, } \\
\text { Mother Language Ratio }\end{array}$} & Lead-in \\
\hline & & Instructions \\
\hline & & Explanation \\
\hline & & Demonstration and Display \\
\hline & & The Use of Mother Language \\
\hline & & Teachers' Response to Students \\
\hline & & Management \\
\hline \multirow{3}{*}{$\begin{array}{l}\text { Student } \\
\text { Learning }\end{array}$} & \multirow{3}{*}{$\begin{array}{l}\text { Learning Style, Learning Time, } \\
\text { State of Concentration \& Preparation }\end{array}$} & Way of dealing with tasks \\
\hline & & Degree of involvement in learning \\
\hline & & Sense of harvest \\
\hline
\end{tabular}

\section{RESULTS AND DISCUSSION}

The text given by the two students is the Reading \& Vocabulary section of My First Ride on a Train, Volume 1, Unit 3 of Compulsory English for Senior One, published by Foreign Language Research Press. The knowledge goal of this unit is to let students master some vocabulary of transportation and related things, and grasp the method of describing tourism experience. The goal of ability is to train students' micro-reading skills. The teaching emphasis is: describing the skills of traveling and using past participle as attributive. The difficulty of teaching is how to use the past tense to describe a trip.

\section{A. Teaching Design}

Three repetitive teaching sessions were conducted in the following steps (Table 2).

TABLE II.

TEACHING STEPS

\begin{tabular}{|c|c|c|}
\hline sessions & Song Wei $(\mathrm{H})$ & Zhao Min (L) \\
\hline 1 & $\begin{array}{l}\text { Introducing the first travel experience by } \\
\text { students---Asking questions about the content of the } \\
\text { text---Summarizing the general idea of the } \\
\text { article---Summarizing the general idea of the } \\
\text { paragraph---Explaining and practicing vocabulary and } \\
\text { grammar---Assigning homework }\end{array}$ & $\begin{array}{l}\text { Introducing the first travel experience by } \\
\text { students---Vocabulary } \\
\text { explanation---Paragraph-by-paragraph } \\
\text { translation---Paragraph-by-paragraph explanation of } \\
\text { grammar---Paragraph-by-paragraph induction of } \\
\text { general idea---Review of knowledge } \\
\text { points---Assigning homework }\end{array}$ \\
\hline 2 & $\begin{array}{l}\text { Picture show--- Introduction of background } \\
\text { knowledge---Questions on text content--- Analysis of } \\
\text { article structure---Students describe their first trip under } \\
\text { the guidance of prompts (who, where, what, etc.) } \\
\text {---Explanations and exercises of vocabulary and } \\
\text { grammar---Summary of this lesson - Homework }\end{array}$ & $\begin{array}{l}\text { Picture show---Vocabulary explanation---Questions } \\
\text { on } \quad \text { text }\end{array}$ \\
\hline 3 & $\begin{array}{l}\text { Picture Show---Background } \\
\text { introduction---Questions on text content---Analysis of } \\
\text { text structure---Vocabulary and grammar explanations } \\
\text { and exercises---Students describe their first trip under the } \\
\text { guidance of prompts (who, where, what, etc.)---Summary } \\
\text { of the main points of this lesson---Homework }\end{array}$ & $\begin{array}{l}\text { Picture show --- } \begin{array}{l}\text { Vocabulary explanation --- } \\
\text { Questions on text content--- }\end{array} \text { Subject } \\
\text { induction---Paragraph summary--- } \text { Grammar } \\
\text { explanation and exercises--- Fill in a form with } \\
\text { prompts such as when, where, what----Brief } \\
\text { description of one trip---Homework }\end{array}$ \\
\hline
\end{tabular}

Combining the above steps with the teaching objectives and difficulties of this unit, we can see that the two students have the same problems in the first session: Not accurately grasping the teaching objectives, nor expressing them in teaching activities, ignoring the analysis of text structure characteristics, abrupt lead-in, raising broad questions that students are unable to answer. The differences lie in: Song Wei follows the teaching ideas from macro to micro, and 
conforms to the cognitive law of comprehensively understanding things. After-class homework is asking the students to summarize texts in writing, which plays a role in training students' refining and expressing abilities. After explaining knowledge points, there are some exercises, which are helpful to cultivate students' language using competence. Zhao Min's method is just the opposite, focusing on the language point, which is easy to convey some one-sided information to students that learning English is to learn words and phrases. After-school homework is to recite some paragraphs, which is quite rigid. Language points are limited to explanation, the ability to use language is ignored completely.

In the second class, Song Wei made great progress: accurately grasping the teaching objectives and carrying out teaching activities closely around the teaching objectives; quickly grasping the students' attention by introducing pictures into the text and also increasing the interest of classroom activities; giving article structure analysis, which is not only conducive to students' better understanding of the text, but also clearly demonstrates the method of describing travel experience; giving useful tips to provide students with scaffolding help, which reduces the obstacles of discourse organization and helps students to use the knowledge learned at present; adding key pints summarizing, which enhances the integrity of teaching steps and deepens students' memory of new knowledge as well; changing after-school homework to write a composition entitled A Trip with the Deepest Memory, which closely follows the teaching objectives. Zhao Min has also made some progress: introducing pictures into texts in a lively and concise way; generally following the teaching logic from macro to micro level; summarizing texts involves the structural features of teaching materials, which are not clear enough, but no longer limited to details such as words and phrases; practicing after explaining knowledge points and paying attention to the ability to use them; assignments after class is a propositional composition My First Trip, which shows that she has a certain understanding and expression of teaching objectives.

In the third class, Song Wei exchanged the steps of knowledge points and students' descriptions of travel experience, which not only made the whole teaching process more logical, but also provided students with the opportunity to use new knowledge; increased the prompt word My views, which was conducive to cultivating students' independent thinking ability; adopting the etymology to explain vocabulary, expanding students' horizons; after-class homework is an either-or writing task: summarizing the text or a journey with the deepest memory, which takes into account students with different language proficiency. After the first two explorations, the teaching activities designed by Zhao Min for the third time clearly expressed the teaching objectives. The overall arrangement of teaching steps also tends to be reasonable. One of the greatest highlights is the use of forms containing prompts to summarize the text, which not only clearly presents the structure and content of the text, but also shows the writing methods of such articles, greatly reducing the difficulty of subsequent oral and writing tasks, paving the way for students to successfully complete the task.

From the above design and analysis, we can see the difference between the two: Song Wei pays attention to the cultivation of language use ability, which provides more opportunities for students to output, supplements the relevant knowledge not appearing in textbooks. Zhao Min pays more attention to memory than to use, gradually appears the opportunity to use language in the later period; the teaching content is limited to textbooks. Additionally, through three teaching sessions, although two students have gradually grasped the teaching objectives and learned how to design teaching activities around them, Song Wei is obviously faster than Zhao Min in terms of growth speed. In terms of the quality of design, Song Wei does also slightly better than Zhao Min: the sequence of textual framework and details makes teaching ideas clear and hierarchical, which is helpful for students to grasp the main idea of the text quickly. Zhao Min's over-emphasis on knowledge points makes the teaching steps less organized and the teaching process less refreshing. The main reasons for these differences are as follows: First, different learning methods. From her own learning experience, Song Wei realized that both input and output are indispensable in English learning. Zhao Min believes that learning English means memorizing and reciting more; a lot of input will naturally bring good output. Second, the consciousness of autonomous learning is different. Song Wei has a strong sense of autonomous learning, thinking that self-study brings a sense of achievement, which makes me want to learn more things. She also holds that arrangement of learning tasks and progress according to her own situation makes her learning more efficient. Zhao Min still stays in the middle school stage where the teacher forces her to go. She is accustomed to cramming education. She learns what the teacher teaches and lacks the consciousness of self-learning. Third, learning habits are different. In the face of new texts, Song Wei usually reads the article first, finds out the general idea, and then looks up new words. This is a structured way of thinking, which can effectively train people's thinking ability and make people think clearly and speak clearly. This is why she can grasp the main points and clarify her ideas in her second class. Zhao Min believes that only by removing the obstacles of new words can she grasp the whole content of the material easily and accurately, so she is used to looking up new words first and then reading the article carefully. This way is easy to let people's attention be occupied by details, but neglect to think about the whole and grasp the core information. This habit delayed her understanding of teaching objectives and logical consideration of teaching steps and accordingly reduced the accuracy and clarity of target expression.

\section{B. Teaching Management}

In the first lesson, the two students have the same problems: The blackboard writing is too arbitrary to reflect the teaching purpose and focus. The teaching equipment is not effectively used. The preset teaching plan is blindly 
completed and the students' reaction is ignored. When calling on the students to participate in classroom activities, they first let the students stand up before issuing instructions, resulting in the students standing nervously and the others sitting watching the lively teaching activities. It takes so long to introduce the text that the main part of the topic is completed in a hurry. The difference is: Song Wei's courseware page content is appropriate. She has a little dependence on courseware. She can occasionally step down from the platform to mobilize students sitting in the middle and front of the classroom to participate in classroom activities. Zhao Min's courseware pages are crowded. She relies heavily on courseware. She stands on the platform all the way, and only mobilizes the students in the first three rows to participate in classroom activities.

In the second lesson, the two students had the same points: The blackboard writing was neat and organized (Song Wei presented the text structure chart and key knowledge points, Zhao Min listed the new words, phrases and grammar), but they did not record the important information in the students' answers and lost the role of assisting students in learning. They used audio equipment to cooperate with picture display. They began to pay attention to students' reactions and adopt repeating and explaining the instructions to help students understand. They asked students to execute the instructions after issuing them, improving students' responsiveness to the instructions. They shortened the lead-in time, leaving enough time for the follow-up steps. The difference is: Song Wei no longer relies on courseware. The frequency of walking off the platform increases and the range of walking expands. She can pay attention to most of the students, but still ignores the students in the corners. Zhao Min's courseware page content has decreased, and her dependence on it has lessened. She can occasionally step down from the platform and pay attention to the students in the middle and front of the classroom, while the students in the back and corners are neglected.

In the third lesson, Song Wei began to record part of the information answered by the students by blackboard, by doing so she helped students solve language difficulties, so as to promote the fluency of classroom activities. She mobilized the vast majority of students to participate in classroom activities, but still lacked effective management means for individual students who did not cooperate. Zhao Min was able to balance the use of courseware and blackboard. She supplemented the contents that are not presented on the blackboard, but still failed to make effective use of its auxiliary teaching function. For example, after introducing the past participle as attributive in theory, she asked a student to translate the sentence of I like the meals cooked by my mother from Chinese to English. After the student answered, she only orally analyzed the translation I like the meals cooked by my Mum, but the sentence is not written on the blackboard for more intuitive explanation. The content of courseware pages was appropriate. She no longer depended on the courseware. The frequency and scope of walking in the classroom has increased, and most students have been concerned. There was still a lack of ability to provide language assistance to students, for example: a student wanted to express navigation system makes our travel more convenient, but he did not know how to express navigation system in English, thus he threw his eyes to the teacher for help. Without a reply, he had to say: 导航系统 makes our travel more convenient, which aroused the laughter of the whole class. Zhao Min had to spend more than a minute to quiet the students.

Generally speaking, there are three differences between them: the degree of dependence on courseware, the scope of attention and mobilization of students, and the ability to provide language assistance. Because of the limited language ability, Zhao Min had to record all the contents in detail in the courseware, which caused the fact of too much content on the first courseware page. In order to avoid making mistakes or omissions, she mostly read the courseware content, which resulted in her over-dependence on the courseware and unable to move freely in order to see the courseware content clearly. Later, with more and more familiar with the content of courseware and gradually reaching the level of lecturing without looking at the screen, her attention gradually turned to the students, and the scope of walking in the classroom gradually expanded. As a result, more and more students were concerned and mobilized. However, providing language assistance belonged to emergencies, which was beyond the scope of preparation. Therefore, she did not give feedback to the students for help. Song Wei's language ability is strong, and she has the ability to improvise. She only needs to record directive information in the courseware, so the content of the page was appropriate and she was less dependent on it. She did not need to look at the screen at any time, so she had a wider range of walking in the classroom, thus paying attention to and mobilizing more students. She has solid language knowledge and has the ability to help students whenever she observes language barriers.

\section{Teacher Language}

In the first lesson, the same problems of the two students are as follows: First, the teaching instructions are lengthy. Such as: I believe all of you have previewed the text in your free time, so, in order to check whether your understanding is right or wrong, I must ask you some questions to check. Second, the demonstration language is complex and logically poor. Third, there is no correction for the students. Forth, there is no careful listening to the students' answers, only simply response with "Good, OK". The difference is: Song Wei mainly used English, and the words were rare, such as: Where did the PROTAGONIST go. Explanatory language was a theoretical description, lacking easy-to-understand concrete examples. Zhao Min used Chinese more frequently. She had more grammatical errors, such as: My meaning is.... She used inaccurate words, such as: Travel expands our eyesight. She had no interpretative language.

In the second lesson, they made the same progress: the instructions were simple and direct, such as the short sentence of please answer me some questions instead of I will check ...; the demonstration language was concise and logical, 
such as the use of first, second, and then etc. to express order. The difference is that Song Wei's uncommon words were reduced and the common words were increased, such as where did the writer go not where did the protagonist go. She began to listen to the students' answers and had simple comments in response. She began to correct the students' errors, but it was limited to the language form and lacked the correction of linguistic meaning and pragmatic errors. Her interpretative language adopted the way of English followed by Chinese to ensure that every student understood them, but some effective methods such as illustrations were still lacking. Zhao Min's got progress in the following aspects: Use of English has increased. Grammatical errors have decreased. Inaccuracy of words has improved. Explanatory language has been adopted, but mainly in Chinese, and only theoretical elaboration has been made. There is still a lack of awareness of error correction and the ability to give specific feedback, for example, a student said: "I have gone to Beijing when I was 6", without correcting, Zhao Min immediately entered the next stage after responding with "OK".

In the third lesson, Song Wei gave specific comments on the students' answers; paid attention to the errors in the form and meaning of the students' language and corrected them in time. For example, one student said: "That's the most wonderful experience I've travelled", and she corrected it as "That's the most wonderful travel experience I can remember". She also began to give explanatory language with examples, such as using the sentence "Rely on your assistant to do his job, but don't depend on him for everything" to help students distinguish rely on from depend on. Zhao Min mostly used English to teach. She gave explanatory language by theory first and then by example, but she mixed more Chinese into English and lacked the ability of explaining in English completely. Grammatical errors are further reduced; students' obvious errors in language form can be occasionally noticed and corrected, such as: go has been changed to went, yesterday night has been changed to last night. Feedback became more specific, such as: "Your description of your traveling experience has brought me to the scene."

From the above process, we can see that Song Wei's progress is rapid, while Zhao Min's progress is slow. This is mainly because they are faced with different language tasks. The main problems Song Wei has to solve are to grasp the students' actual level and to reduce the complexity of language accordingly so as to facilitate students' understanding. Zhao Min should not only consider the complexity of language, but also the accuracy and fluency. However, the limitation and uncertainty of her own linguistic knowledge make her unable to take these three aspects into account at the same time. Only through after-class reflection can she correct the mistakes or inappropriateness of this lecture and make better preparations for the next lecture. So she is making passive and little progress. But the students' mistakes are unpredictable and beyond the scope of preparation, so she only corrected the errors she was sure of and let go of those she was uncertain of. As she said in the interview: "I know the students' expressions are wrong, but I did not know how to correct them at that time."

\section{Student Learning}

In the first class, the students of the two classes have the same points: Part of them are active and part of them are indifferent in the degree of investment in learning. Nearly half of the students can not complete the teaching tasks within the prescribed time. The difference lies in the students 'sense of harvest: The students in Song Wei's class think that the teacher has explained the grammar clearly, and they fully understand those points. While most of the students in Zhao Min's class think that they have not learned anything useful.

In the second lesson, two-thirds of the students in Song Wei's class can actively participate in the teaching activities, complete the teaching tasks within the prescribed time, and think that there are gains in the textual layout, vocabulary and grammar. Zhao Min has also improved student participation, but due to the lack of scaffolding information, task completion time is longer and the quality is inferior. The students believe that there are gains in text understanding and grammar learning.

In the third lesson, the students in Song Wei's class can successfully complete the teaching activities and have a strong sense of harvest. Especially explaining words from the perspective of etymology makes them think that the teacher is so great and the etymology makes them open-minded, they can remember many words at once and feel that words are not dead, but live in front of their eyes. In Zhao Min's class, due to the adjustment of teaching steps and the help of scaffolding information, students' participation has been greatly improved, and they can better complete the teaching tasks within the prescribed time. Students have a stronger sense of harvest and think that they have a clear grasp of the structure and content of the text, and also learn how to use the new knowledge points.

From the above feedback, we can see that Song Wei's teaching is more conducive to students' learning. This is first because she has formed a complete and systematic knowledge structure and thus can clearly and thoroughly narrate knowledge points. Secondly, she has a wide range of knowledge and can expand the content of the text freely. For example, when introducing Australia, she first introduced the word commonwealth, and then made an analysis and illustration of its composition and usage. Thirdly, she has effective learning methods. For example, when speaking about the new word commercial, she first outlines the story of Mercury, the God of Commerce in Greek mythology, and guides students to draw the conclusion that Merc represents commerce. Then she uses the homologous words merchant and mercy to prove and expand, which not only arouses students' interest, but also imparts learning methods. Zhao Min's knowledge is scattered and fragmented. She has not established the connection between knowledge points, can't extract it at any time and can't give a point-to-point divergent explanation. Therefore, her teaching content lacks depth and breadth, which is not conducive to students' learning. 


\section{CONCLUSION}

This study shows that language proficiency is closely related to teaching knowledge learning of the students at a normal school. On the surface, it seems that language proficiency has caused the difference of acquisition of teaching knowledge, but from the root, it is the learning attitude, learning methods and other factors that determine the language proficiency that determine the students' acquisition of teaching knowledge. Therefore, in the basic stage of pre-service teacher's training, i.e. freshmen and sophomores, teacher educators should focus on establishing the correct learning attitude of the students, helping them find appropriate learning methods and effectively improving their learning ability. This can not only effectively improve their English level, but also fundamentally promote their teachers' learning in the future.

\section{ACKNOWLEDGMENTS}

The research is supported by the 9th China Foreign Language Education Fund (No.: ZGWYJYJJ2018B100), Education and Teaching Research and Reform in Sichuan University of Arts and Science (No.: 2017JY13).

\section{REFERENCES}

[1] Ball, D. L. \& McDiarmid, G. W. (1990). The subject-matter preparation of teachers. In W. R. Houston and M. H. J. Sikula (Eds.), Handbook of research on teacher education. New York: Macmillan,437-449.

[2] Borg, S. (1998). Teachers' pedagogical systems and grammar teaching: A qualitative study. TESOL Quarterly, 32(1), 9-37.

[3] Chen Shuang \& Zou WeiCheng. (2016). A study on teacher learning of English majors at the normal university in repetitive classroom teaching. China Foreign Language, 3, 65-72.

[4] Grossman, P. L. (1990). The making of teacher: Teacher knowledge and teacher education. New York: Teacher College Press.

[5] Shulman, L. (1987). Knowledge and teaching: Foundations of the new reform. Harvard Educational Review, 1, 1-21.

[6] Xie Peiyun \& Zou Weicheng. (2015). Narrative study on practical knowledge of new English teachers. Foreign Language Research, 4, 57-62.

[7] Zou Weicheng. (2013). How does practical experience change the knowledge structure of foreign language teachers? Chinese Foreign Languages, 10, 72-80.

[8] Zou Bin \& Chen Xiangming. (2005). Traceability of teacher's knowledge concept. Course, Textbook, Teaching Method, 6 , 85-89.

Mingmei Wang was born in Dazhou, China in 1976. She received her M.A. in linguistics and applied linguistics from Chongqing University, China in 2008.

She is currently an associate professor in the School of Foreign Languages, Sichuan University of Arts and Science, Dazhou, China. Her research interests include applied linguistics and teacher education. 